\title{
SYNTHESIS OF $\operatorname{In}_{2} \mathrm{O}_{3}$ NANOWIRES FOR THE APPLICATION OF LPG SENSOR
}

\author{
Sh. Romeo Meitei ${ }^{1}$, Naorem Khelchand Singh ${ }^{2}$ \\ ${ }^{l}$ Department of Electronics and Communication Engineering, National Institute of Technology, Nagaland, \\ Chumukedima, Dimapur, Nagaland-797103, India \\ ${ }^{2}$ Department of Electronics and Communication Engineering, National Institute of Technology, Nagaland, \\ Chumukedima, Dimapur, Nagaland-797103, India
}

\begin{abstract}
$\mathrm{In}_{2} \mathrm{O}_{3}$ nano-column arrays are synthesized on p-type Si substrate by glancing angle deposition technique (GLAD). Indium Oxide is a wide-band gap Semiconductor which shows prospective potential for gas sensors. After the deposition is completed, the Crystallinity and the Orientation of the as-deposited Indium Oxide Nanowires are observed using the X-ray Diffractometer $(X R D)$. Extrapolation of the linear part of the curve to the $h v$-axis from $E V s(\alpha h v)^{2}$ graph from optical absorption spectrum yields a bandgap close to $3.3 \mathrm{eV}$. Silver (Ag) contact is made over $\mathrm{In}_{2} \mathrm{O}_{3}$ nanowires to form $\mathrm{In}_{2} \mathrm{O}_{3} \mathrm{LPG}$ sensing device. At $2 \mathrm{~V}$, under exposure to LPG, the device shows nearly 5 times enhancement in the sensitivity as compared to exposure in ambient atmosphere. This result clearly indicates that $\mathrm{In}_{2} \mathrm{O}_{3} \mathrm{NW}$ device is a very good contender for efficient and cost effective LPG sensor if fabricated commercially on large scale
\end{abstract}

Keywords: $\quad G L A D, I_{2} O_{3}$ Nanowire, XRD, SEM, Optical absorption, Photoluminescence (PL), electrical characteristics

\section{INTRODUCTION}

Indium oxide is a wide band gap $(\sim 3.6 \mathrm{eV})[1]$, transparent and highly conducting [2]. Because of these properties it has its application in sensors and detectors [3-6]. There are different techniques for fabricating one dimensional In2O3 nanostructure, they are thermal evaporation [7-8], pulse laser ablation [9], chemical vapour deposition [10], sputtering [11], vapour liquid solid condensation [12], atomic vapour deposition [13]. The main disadvantage with the above mentioned techniques is that the nanostructures obtained are not perpendicularly grown on the substrate. Perpendicular and well patterned [14] NW array is very much essential to obtain high surface-to-volume ratio, which in turn will greatly enhance the sensitivity of the fabricated nanostructure by facilitating large surface area for reaction to take place. With the help of GLAD technique the growth and orientation of nanowire [15] can be controlled effectively. GLAD technique is an effective technique for vertically growing well patterned NW on the substrate. In this study we have synthesized the vertically oriented In2O3 NW arrays on Si substrate by using GLAD technique inside e-beam evaporator. The characterization of the fabricated samples has been discussed.

Liquefied petroleum gas (LPG) is utilized in almost every kitchen all over the world. It is therefore, referred as a town gas or cooking gas. Along with inevitable domestic use, it is utilized in large extent for industrial purposes and in laboratories as fuel. Cooking gas consists mainly of butane and propane, which are colourless and odourless gases [1719]. It is usually mixed with compounds of sulphur (viz. methyl mercaptan and ethyl mercaptan) having foul smell, so that its leakage can be noticed easily. This gas is potentially hazardous because explosion accidentsmight be caused when it leaks out by mistake. It has been reported that, at the concentration up to noticeable leakage, it is very much more than the lower explosive limit (LEL) of the gas in air. Explosion accidents destroyed many industries, laboratories, kitchens and houses, buildings, societies and what not? Due to the increased awareness of potential explosive in bothindustrial and domestic environments, there is a growing need todetect and monitor LPG. Many researchers are working on LPG sensor, but could not meet the challenges up to the depth of demand by society. So, there is a great demand from the society of detecting LPG for the purpose of safety applications in domestic and industrial fields.

\section{EXPERIMENTAL PROCEDURE}

\subsection{Synthesis of $\mathrm{In}_{2} \mathrm{O}_{3} \mathrm{NW}$ and Device Fabrication}

$\mathrm{In}_{2} \mathrm{O}_{3} \mathrm{NW}$ arrays were synthesized on the P-type $\mathrm{Si}<100>$ substrate. With the help of GLAD technique $\operatorname{In}_{2} \mathrm{O}_{3} \mathrm{NW}$ were deposited over cleaned $1 \mathrm{~cm}$ x $1 \mathrm{~cm}$ p-type Si substrate inside E-beam evaporation chamber. The substrate was cleaned successively using electronic grade acetone, methanol and $18 \mathrm{M} \Omega$ DI water, rinsed for $10 \mathrm{sec}$ in each solvent. The deposition was carried out at a chamber pressure of around $\sim 1 \times 10^{-5}$ mbar. A constant growth rate of $1.2 \mathrm{~A} \mathrm{~s}^{-1}$ was maintained throughout the deposition process. For achieving vertical growth of NW, the substrate were kept at $85^{\circ}$ with respect to the perpendicular line 
between the material source and the planar substrate and a separation of $24 \mathrm{~cm}$ is kept between substrate holder and Ebeam source. Azimuthal rotation of $120^{\circ}$ is maintained for synthesis of NW. $\operatorname{In}_{2} \mathrm{O}_{3}$ LPG sensing device is fabricated by deposition of $\operatorname{In}_{2} \mathrm{O}_{3}$ TF over the Si substrate, then $\operatorname{In}_{2} \mathrm{O}_{3} \mathrm{NW}$ were grown over the TF using GLAD, Ag (silver) contacts were made over the NW. Ag was evaporated through the aluminum mask having holes of diameter $2 \mathrm{~mm}$ on top of $\mathrm{In}_{2} \mathrm{O}_{3} \mathrm{NW}$ to get a schottky contact.

\section{CHARACTERIZATION}

XRD analysis was done by D8 ADVANCE ECO BRUKER using $\mathrm{CuK} \alpha$ radiation. The Photoluminescence (PL) study was carried out at room temperature using F-7000 FL spectrometer. The optical absorption analysis was carried out using UV-Vis spectrophotometer. The electrical characteristics of the device $\left(\mathrm{Ag} / \mathrm{In}_{2} \mathrm{O}_{3}-\mathrm{NW} / \mathrm{In}_{2} \mathrm{O}_{3}-\mathrm{TF} / \mathrm{Si}\right)$ were studied by using Keithley 2400 source measure unit. The response of the device was studied both in presence and in absent of LPG.

\section{RESULT AND DISCUSSION}

Figure 2(a) shows the X-ray diffraction (XRD) analysis of the as deposited $\operatorname{In}_{2} \mathrm{O}_{3} \mathrm{NW}$ which shows the presence of different phases i.e. (222),(400) and (004). The phases at (222) and (400)are attributed to $\mathrm{In}_{2} \mathrm{O}_{3}$ [JCPDS, 06-0416] [20]. The diffraction pattern from 004 is also observed which is due to $\mathrm{Si}$ substrate [JCPDS, 27-1402] [21-22]. Therefore, the XRD pattern reveals the polycrystalline nature of the deposited $\operatorname{In}_{2} \mathrm{O}_{3} \mathrm{NW}$.

\section{OPTICAL CHARACTERIZATION}

Optical absorption measurement was carried out on $\operatorname{In}_{2} \mathrm{O}_{3}$ $\mathrm{NW/Si}$ Nanostructure samples in the wavelength range of 200-800 nm at room temperature. Enhance absorption was observed from $\mathrm{In}_{2} \mathrm{O}_{3} \mathrm{NW}$ sample both in the visible and UV region (Fig 2(b)), which is due to their large surface area to volume ratio of the $\mathrm{In}_{2} \mathrm{O}_{3} \mathrm{NW}$ [23]. Fig 2(c) shows the $(\alpha h v)^{2}$ versus (hv) for the as deposited $\mathrm{In}_{2} \mathrm{O}_{3} \mathrm{NW}$ sample, where hv is the sample energy and $\alpha$ is the absorption of each wavelength which is given by $\alpha=\frac{4 \pi \mathrm{k}}{\lambda}$, where $\mathrm{k}=$ absorption index.. The value of band gap was determined by extrapolating the straight line portion of the $(\alpha h v)^{2}$ on the $x-$ axis. From the graph, we have seen the optical band gap value close to $\sim 3.3 \mathrm{eV}(375 \mathrm{~nm})$. Multiple scattering of incident photon occurs between consecutive vertically grown $\mathrm{NW}$, as a result the $\mathrm{NW}$ absorbed most of the incident photon. Fig 2(d) shows the PL spectrum of $\operatorname{In}_{2} \mathrm{O}_{3}$ NW grown over Si substrate. The PL measurement has been carried out at room temperature on the as deposited $\operatorname{In}_{2} \mathrm{O}_{3}$ NW using an excitation wavelength of $250 \mathrm{~nm}$. The band gap of the $\mathrm{In}_{2} \mathrm{O}_{3}$ can also be estimated from the peaks in the photoluminescence (PL) curve. From the figure, maximum peak is observed at the wavelength $\lambda=346.78 \mathrm{~nm}(3.57 \mathrm{eV})$. PL emissions are possibly due to the effect of oxygen vacancy [24].

\section{ELECTRICAL CHARACTERISTICS}

Fig 3 shows the Plot between Current density and voltage. The black curve indicates the response of the fabricated device when it is exposed to ambient atmosphere. When the device is exposed to atmosphere, atmospheric oxygen $\left(\mathrm{O}_{2}\right)$ will get absorbed onto the surface of $\mathrm{In}_{2} \mathrm{O}_{3} \mathrm{NW}$, thereby forming a layer of $\mathrm{O}^{-}$(ion) on the $\mathrm{NW}$ surfaces. These $\mathrm{O}^{-}$ will become the active sites for the absorption of different constituent of LPG. The red curve indicates the response of the device when exposed to LPG.The turn ON voltage for the device in ambient atmosphere is found out to be $2 \mathrm{~V}$, on exposure to LPG it reduces to $0.15 \mathrm{~V}$. It is very clear from graph that there is significant improvement in device response when exposed to LPG, this is due to the release of extra electrons, when $\mathrm{O}^{-}$(ion) attached to $\mathrm{In}_{2} \mathrm{O}_{3} \mathrm{NW}$ react with LPG.

$$
\mathrm{C}_{4} \mathrm{H}_{10}+13 \mathrm{O}^{-} \longleftrightarrow 4 \mathrm{CO}_{2}+5 \mathrm{H}_{2} \mathrm{O}+13 \mathrm{e}^{-}
$$



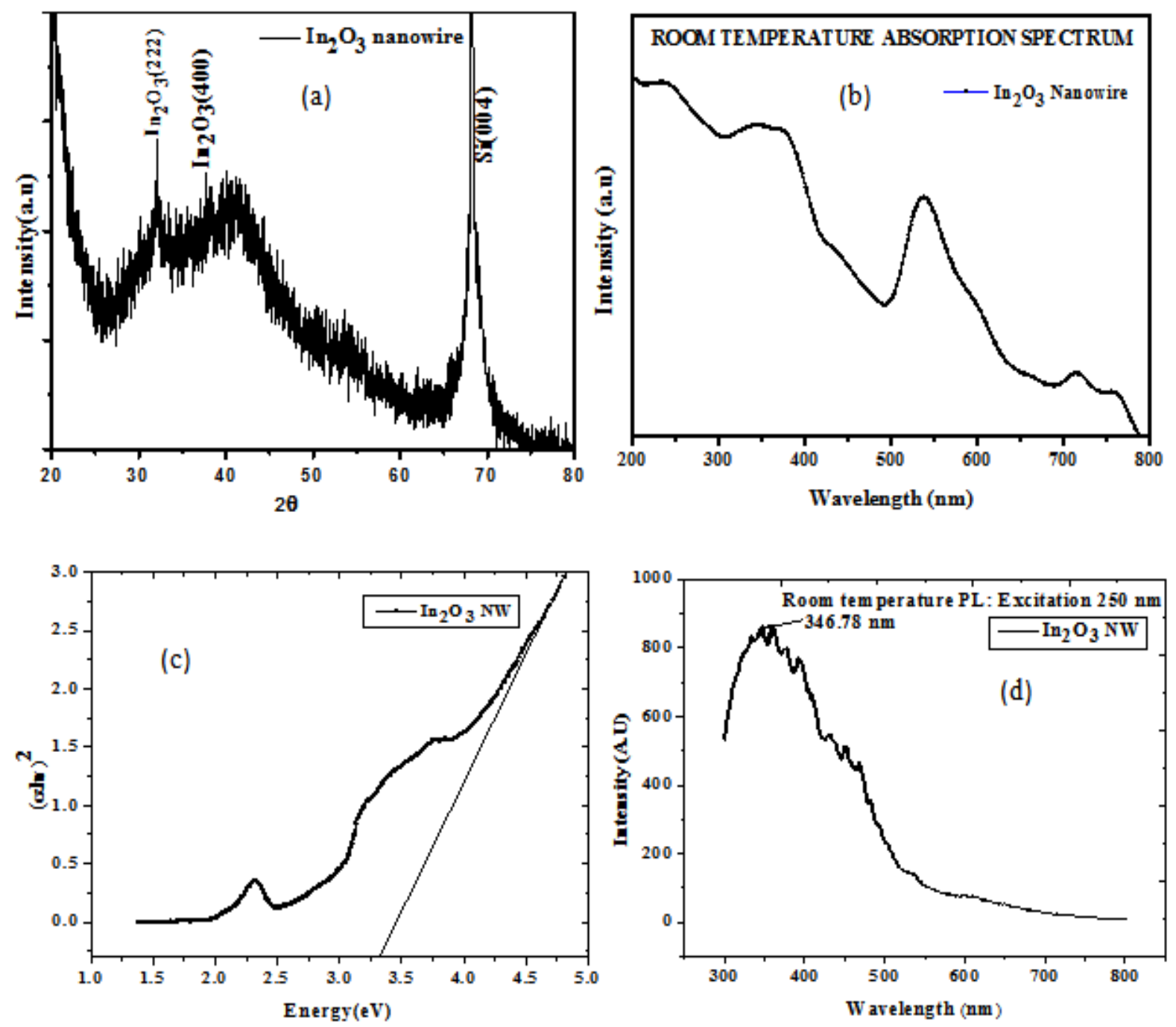

Fig.2: (a) XRD pattern of as deposited $\mathrm{In}_{2} \mathrm{O}_{3} \mathrm{NW} / \mathrm{Si}$ nanostructure (b) Room Temperature Optical absorption spectrum of $\mathrm{In}_{2} \mathrm{O}_{3}$ NW/Si Nanostructure. (c) ( $\alpha \mathrm{hv})^{2}$ Vs Energy curve and (d)Room temperature Photoluminescence spectrum of $\operatorname{In}_{2} \mathrm{O}_{3} \mathrm{NW}$.

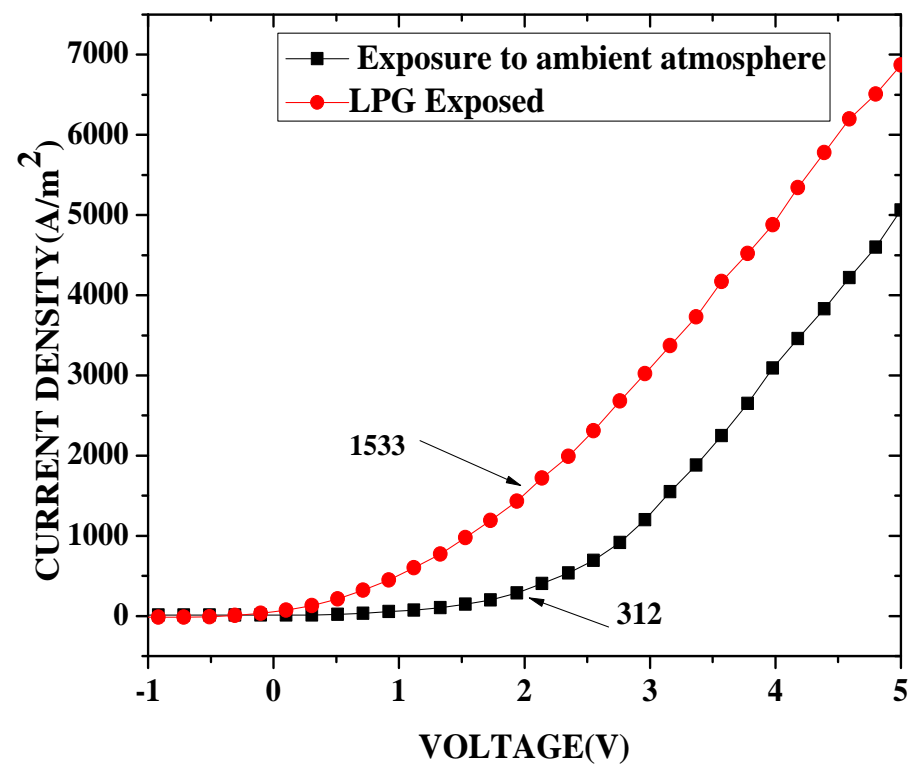

Fig.3: Current density versus Voltage 


\section{LPG SENSING MECHANISM}

The gas sensing mechanism (fig.4) can be explained in terms of conductance by absorption of atmospheric oxygen on the surface of the $\operatorname{In}_{2} \mathrm{O}_{3} \mathrm{NW}$ with the LPG [25]. The atmospheric oxygen absorbs on the surface by extraction of electrons from conduction band are mainly responsible for the detection of LPG which can be shown as:

$$
\mathrm{O}_{2(\text { air })}+2 \mathrm{e}_{\text {(cond. band) }}^{-} \longrightarrow 2 \mathrm{O}_{(\mathrm{NW} \text { surface })}^{-}
$$

It would result in decreasing conductivity of the device when LPG reacts with the absorbed oxygen on the surface of the NW, LPG constituent gases are oxidized to $\mathrm{CO}_{2}$ and $\mathrm{H}_{2} \mathrm{O}$ following a series of intermediate stages. This liberates free electrons in the conduction band. The final reaction takes place as

$$
\mathrm{C}_{4} \mathrm{H}_{10 \text { (gas) }}+13 \mathrm{O}^{-} \text {(NW surface) } \longrightarrow 4 \mathrm{CO}_{2 \text { (gas) }}+5 \mathrm{H}_{2} \mathrm{O}_{\text {(gas) }}+13 \mathrm{e}^{-}
$$

These generated electrons contribute to a sudden increase in conductance of the fabricated device.

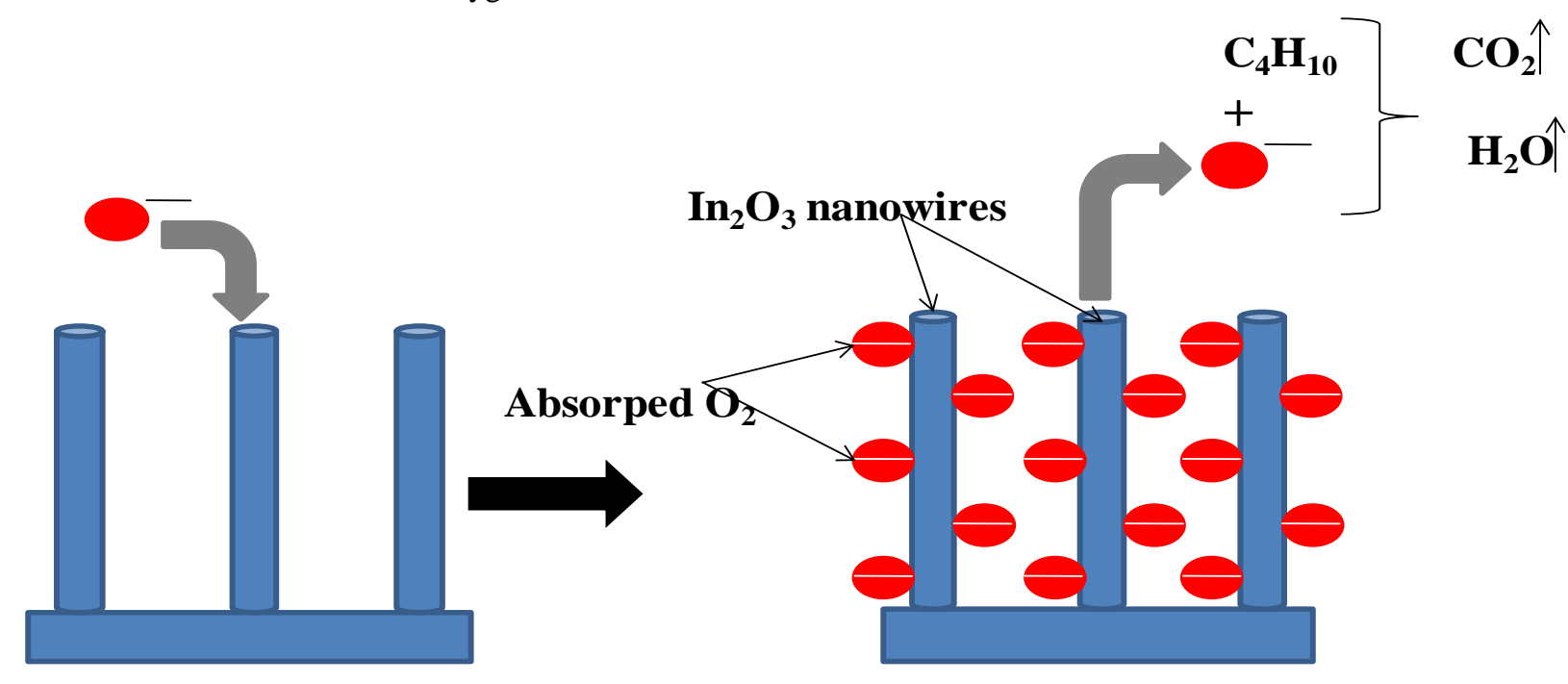

$$
\mathrm{C}_{4} \mathrm{H}_{10}+13 \mathrm{O}^{-} \longleftrightarrow 5 \mathrm{H}_{2} \mathrm{O}+4 \mathrm{CO}_{2}+13 \mathrm{e}^{-}
$$

Fig 4: Oxygen absorption mechanism

\section{CONCLUSION}

In summary, we have fabricated the $\operatorname{In}_{2} \mathrm{O}_{3}$ nanowires by using e-beam evaporation method with the help of GLAD technique.. XRD analysis reveals the polycrystalline nature of the nanostructure. And the absorption spectrum reveals that the nanostructure exhibited a wide range of absorption ranging from 330- $400 \mathrm{~nm}$ wavelength due to the presence of $\mathrm{In}_{2} \mathrm{O}_{3} \mathrm{NW}$ which makes it suitable for a UV-Viz detectionalso. It is also found that at $2 \mathrm{~V}$ there is 5 times device response improvement when exposed to LPG. This result clearly indicated that $\operatorname{In}_{2} \mathrm{O}_{3} \mathrm{NW}$ based device is a very good contender for efficient and cost effective LPG sensor if fabricated commercially on large scale.

\section{ACKNOWLEDGEMENT}

The authors thank the Semiconductor Lab, NIT Nagaland for giving the facility of device fabrication, the chemistry department NIT Manipur for PL measurement and XRD measurement, NIT Agartala for optical measurement, and the physics department NIT Nagaland for XRD measurement.

\section{REFERENCES}

[1] Murali, A., Barve, A., Leppert, V.J., Risbud, S.H., Kennedy, I.M. and Lee, H.W., 2001. Synthesis and characterization of indium oxide nanoparticles. Nano Letters, 1(6), pp.287-289.

[2] Bierwagen, O. and Speck, J.S., 2010. High electron mobility In2O3 (001) and (111) thin films with nondegenerate electron concentration. Applied Physics Letters, 97(7), p.072103.

[3] Shen, G., Chen, P.C., Ryu, K. and Zhou, C., 2009. Devices and chemical sensing applications of metal oxide nanowires. Journal of Materials Chemistry, 19(7), pp.828-839.

[4] Ju, S., Facchetti, A., Xuan, Y., Liu, J., Ishikawa, F., Ye, P., Zhou, C., Marks, T.J. and Janes, D.B., 2007. Fabrication of fully transparent nanowire transistors for transparent and flexible electronics. Nature nanotechnology, 2(6), pp.378-384.

[5] Wu, Z.H., Mei, X., Kim, D., Blumin, M., Ruda, H.E., Liu, J.Q. and Kavanagh, K.L., 2003. Growth, branching, and kinking of molecular-beam epitaxial< 110> GaAs nanowires. Applied physics letters, 83(16), pp.3368-3370. 
[6] Leung, Y.P., Liu, Z. and Hark, S.K., 2005. Changes in morphology and growth rate of quasi-onedimensional $\mathrm{ZnSe}$ nanowires on GaAs (100) substrates by metalorganic chemical vapor deposition. Journal of crystal growth, 279(3), pp.248257.

[7] Veeraswamy, Y., Vijayakumr, Y. and Reddy, M.R., 2013, July. Structural and optical characterization of indium oxide thin films by vacuum thermal evaporation. In Advanced Nanomaterials and Emerging Engineering Technologies (ICANMEET), 2013 International Conference on (pp. 502-505). IEEE.

[8] Jeong, J.S. and Lee, J.Y., 2011. Formation mechanism and photoluminescence of necklace-like In 2 O 3 nanowires. Materials Letters, 65(11), pp.1693-1695.

[9] Beena, D., Lethy, K.J., Vinodkumar, R., Detty, A.P., Pillai, V.M. and Ganesan, V., 2010. Photoluminescence in laser ablated nanostructured indium oxide thin films. Journal of Alloys and Compounds, 489(1), pp.215-223.

[10] Wang, G., Park, J., Wexler, D., Park, M.S. and Ahn, J.H., 2007. Synthesis, characterization, and optical properties of $\mathrm{In} 2 \mathrm{O} 3$ semiconductor nanowires. Inorganic chemistry, 46(12), pp.4778-4780.

[11] Tait, R.N., Smy, T. and Brett, M.J., 1993. Modelling and characterization of columnar growth in evaporated films. Thin Solid Films, 226(2), pp.196201.

[12] Schmidt, D., Müller, C., Hofmann, T., Inganäs, O., Arwin, H., Schubert, E. and Schubert, M., 2011. Optical properties of hybrid titanium chevron sculptured thin films coated with a semiconducting polymer. Thin Solid Films, 519(9), pp.2645-2649.

[13] Carter, C.B. and Williams, D.B., 2009. Transmission electron microscopy. Springer-Verlag US.

[14] Di Giacomo, G. and Di Giacomo, G., 1997. Reliability of electronic packages and semiconductor devices. New York: McGraw-Hill.

[15] Jie, J., Wang, G., Han, X., Yu, Q., Liao, Y., Li, G. and Hou, J.G., 2004. Indium-doped zinc oxide nanobelts. Chemical Physics Letters, 387(4), pp.466470.

[16] Lin, X., He, X.B., Yang, T.Z., Guo, W., Shi, D.X., Gao, H.J., Ma, D.D.D., Lee, S.T., Liu, F. and Xie, X.C., 2006. Intrinsic current-voltage properties of nanowires with four-probe scanning tunneling microscopy: A conductance transition of $\mathrm{ZnO}$ nanowire. Applied physics letters, 89(4), p.043103.

[17] Patil, D.R. and Patil, L.A., 2009. Cr 2 O 3-modified $\mathrm{ZnO}$ thick film resistors as LPG sensors. Talanta, 77(4), pp.1409-1414.

[18] Ghosh, A., Sharma, R., Ghule, A., Taur, V.S., Joshi, R.A., Desale, D.J., Gudage, Y.G., Jadhav, K.M. and Han, S.H., 2010. Low temperature LPG sensing properties of wet chemically grown zinc oxide nanoparticle thin film.Sensors and Actuators $B$ : Chemical, 146(1), pp.69-74.
[19] Sahay, P.P. and Nath, R.K., 2008. Al-doped zinc oxide thin films for liquid petroleum gas (LPG) sensors. Sensors and Actuators B: Chemical, 133(1), pp.222-227.

[20] Peng, X.S., Wang, Y.W., Zhang, J., Wang, X.F., Zhao, L.X., Meng, G.W. and Zhang, L.D., 2002. Large-scale synthesis of In2O3 nanowires. Applied Physics A, 74(3), pp.437-439.

[21] Hatchard, T.D. and Dahn, J.R., 2004. In situ XRD and electrochemical study of the reaction of lithium with amorphous silicon. Journal of The Electrochemical Society, 151(6), pp.A838-A842.

[22] Takamura, T., Ohara, S., Uehara, M., Suzuki, J. and Sekine, K., 2004. A vacuum deposited Si film having a Li extraction capacity over $2000 \mathrm{mAh} / \mathrm{g}$ with a long cycle life. Journal of Power Sources, 129(1), pp.96100.

[23] Mondal, A., Shougaijam, B., Goswami, T., Dhar, J.C., Singh, N.K., Choudhury, S. and Chattopadhay, K.K., 2014. Structural and optical properties of glancing angle deposited In2O3 columnar arrays and Si/In2O3 photodetector. Applied Physics A, 115(1), pp.353-358.

[24] Zhang, J., Qing, X., Jiang, F. and Dai, Z., 2003. A route to Ag-catalyzed growth of the semiconducting In 2 O 3 nanowires. Chemical physics letters,371(3), pp.311-316.

[25] Patil, D.R. and Patil, L.A., 2009. Cr 2 O 3-modified $\mathrm{ZnO}$ thick film resistors as LPG sensors. Talanta, 77(4), pp.1409-1414. 